\title{
Writing Strategies Used by ESL Upper Secondary School Students
}

\author{
Nooreiny Maarof ${ }^{1} \&$ Mazlin Murat ${ }^{2}$ \\ ${ }^{1}$ Faculty of Education, Universiti Kebangsaan Malaysia, Malaysia \\ ${ }^{2}$ Ministry of Education, Malaysia \\ Correspondence: Nooreiny Maarof, Faculty of Education, Universiti Kebangsaan Malaysia, Bangi 43600, \\ Selangor, Malaysia. Tel: 603-8921-6269. E-mail: noreiny@ukm.my
}

Received: January 15, 2013 Accepted: January 29, 2013 Online Published: March 7, 2013

doi:10.5539/ies.v6n4p47 URL: http://dx.doi.org/10.5539/ies.v6n4p47

\begin{abstract}
Writing is a great challenge whether performed in the mother tongue or in a second or foreign language (L2/FL). Studies in L2 writing show that writing is a complex cognitive activity comprising a number of processes which includes the use of various strategies. This study aimed to examine strategies used in essay writing among 50 high-intermediate and low proficiency ESL upper secondary school students and to determine any significant differences in strategy use between the two groups. Data from the Writing Strategy Questionnaire indicate that the ESL students were moderate writing strategies users. The while-writing strategies were most frequently used whereas the revising strategies were least used. All students displayed approximately similar frequency use of strategies. They differed only in the type of strategies used. An implication of the study is that students need to be encouraged to use various strategies in improving their writing. Strategy training for ESL students is important to help them write successfully in the target language.
\end{abstract}

Keywords: writing strategies, ESL students, proficiency levels

\section{Introduction}

For many students, writing presents a great challenge whether writing in the mother tongue or the foreign language. Nunan (1999) states that the most difficult task to do in language learning is to produce a coherent, fluent, extended piece of writing, which is even more challenging for second language learners. Writing is seen as a process whereby writers discover and reformulate ideas as they attempt to create meaning. It can be viewed as a problem solving activity rather than a simple act of communication. In approaching writing tasks, writers are actually searching for solutions to a series of problems (Hyland, 2008). Therefore, writing is a complex cognitive activity comprising a number of processes and strategies. The use of strategies in the writing process is crucial to successful writing. The key to producing good writing or essays relies on the types and amount of strategies used, and on the regulation of the strategies for generating ideas or for revising what has been written (Riduan \& Lim, 2009).

Writing is a basic skill that needs to be mastered by all students in the Malaysian English Language curriculum (Ministry of Education Malaysia, 2000). Despite learning English for many years, many of these students remain weak in the English language, especially in their writing skills (Rashidah, 2005). Chitravelu, Sithamparam and Teh (2005) pointed out that writing is the skill most Malaysian students are less proficient in and they do not know how to accomplish the written tasks in satisfactory ways.

The analysis of the national examination performance by the Examination Division, Malaysian Ministry of Education showed that less than twenty percent (20\%) of the Malaysian Certificate of Education or Sijil Pelajaran Malaysia (SPM) candidates had obtained distinctions (Grade A) for the standardized national SPM English 1119 paper (Malaysian Examinations Council, 2009). This weak performance may reflect the candidates' inability to accomplish the writing task effectively. Since the writing section of the SPM English 1119 makes up a larger percentage of the examination total score, the low scores obtained for the writing task had affected the overall performance of the students for the English paper.

The $\mathrm{L} 2$ writing process is strategically, rhetorically and linguistically different from the L1 writing processes and novice L2 writers must be taught L2 writing strategies explicitly (Mu \& Carrington, 2007). However, students are seldom guided on the use of strategies in the process of writing that could help them to become good writers. Teachers provide little guidance to their students on writing strategies because they may have a poor 
understanding of their students' knowledge of writing. Thus, there is a crucial need for English teachers to better understand the strategies used by their students in their writing tasks.

The main aim of the preliminary study is to identify the strategies used in essay writing among ESL students of different level of proficiency. The study also attempts to determine whether students of different proficiency levels employ different strategies in the three stages of writing: prewriting, writing and revising.

\subsection{Writing Strategies in Second Language}

Research on the L2 writing process began since the early 1980s (for example, Lay, 1982; Raimes, 1985; Zamel, 1983, among others). L2 writing is a complex process of discovery which involves brainstorming, multiple drafting, feedback practices, revision, and final editing. It is different from L1 writing in that ESL writers (L2) have more than one language at their disposal (Wang \& Wen, 2002). Studies on the L2 writing process have also identified various specific writing strategies used by L2 writers. Writers with different proficiency levels tend to use different strategies. Zamel (1983) found that the skilled ESL writers in the study revised more and spent more time on their essays than the unskilled ESL writers. The skilled ESL students were more concerned with the ideas first, revised at the discourse level, displayed recursiveness in their writing process and in the editing done at the end of the process. The unskilled ESL student writers, however, revised less and spent less time writing compared to the skilled students. Raimes' (1985) protocol-based study of eight unskilled ESL students revealed that the L2 writers did minimal planning before or during writing, paid less attention to revising and editing and kept rereading their work to develop ideas. An investigation of the composing process of ESL learners, primarily focussing on revision and editing, highlighted the importance of revision and editing in the production of successful essays (Polio, Fleck \& Leder, 1998). Siti Hamin and Abdul Hameed's (2006) study on Malaysian Malay ESL students found that generating ideas using L1among students with low English proficiency helped them to produce higher quantity of ideas and better quality essays in terms of overall score, content, language, organization, vocabulary and mechanics. Cumming (1989) had earlier reported that all six of his Francophone Canadian adult subjects tended to use the L1 for generating content for their writing tasks. The inexpert writers consistently used their L1 to generate ideas while the expert writers used L1 for generating content and lexical searches.

\subsection{Writing Strategies and English Proficiency}

The role of writing strategies in the process of writing has become increasingly important and differences between more and less proficient learners have been found in the number and range of strategies used, in how the strategies are applied to the task, and in appropriateness of the strategies for the tasks (Chien, 2010; Hu \& Chen, 2007; Mu \& Carrington, 2007; Ridhuan \& Abdullah, 2009). This implies the interplay of a number of factors for successful application of writing strategies. Having a number and range of strategies for instance is useful, but students' understanding of the requirements of the writing tasks and the use of appropriate strategies to carry out the task often determine the effectiveness of the strategies used.

Planning strategies have been found to be significant to skilled student writers (Mu \& Carrington, 2007; Ridhuan \& Abdullah, 2009). In comparison, the literature shows that many low achievers reported less use of these strategies (Chien, 2010). Weak students do not often plan their writing and frequently begin writing immediately (Ridhuan \& Abdullah, 2009). On the other hand, skilled students differ in terms of time spent on planning the writing task. They usually employ drafting to produce rough plans on how to present their essays and thus, spend more time on planning (Ridhuan \& Abdullah, 2009). Hu and Chen (2007) observed that good ESL writers weigh carefully on decisions on what to write and on how to proceed, indicating the importance of quality of planning over time spent planning. Weak student writers, however, typically spent a longer time although such efforts failed to generate ideas, and plans developed globally were mostly ineffective. In her observation of the writing behaviours of four writers from different cultural backgrounds, Indra (2004) found that the good Chinese writer in her study planned his ideas using outlines whereas the good Indian writer planned by putting down visual representations. In contrast, the other two weak student writers spent a longer time for planning which was done mentally, and the effort somehow proved to be ineffective in helping them to develop ideas for their writing task.

Ridhuan \& Abdullah (2009) reported that good students and weak students in his study shared common writing strategies, mainly cognitive strategies, to generate ideas for their essays. The strategies included transcribing, rehearsing ideas, rehearsing structure, rereading, translating and repeating. Chien (2010) on the other hand claimed that the high achievers in his study focused more on generating text (writing out the sentences) while the low achievers focused only on generating ideas.

Another important strategy that differentiates the skilled students and less skilled student writers is the revising strategy. According to Chien (2010), high achievers in his study focused on revising and editing. In addition, 
they perceived writing as a process to express ideas. The good writers made meaningful changes, a way of thinking and clarifying meanings for themselves, and did not concentrate only on mechanics. Mu and Carrington (2007) reported that for the participants in their study, content revision was considered most important followed by structure and vocabulary. In contrast, all writers including skilled writers in Hu and Chen's (2007) study revised mostly lexical and grammatical elements rather than the discourse structure which reflects a surface writing approach.

A recent study by Chen (2011) that investigated the English writing strategies of 132 Chinese, non-English major college students found that although the students used some writing strategies in the pre-writing stage, while-writing stage and revising stage, they were still not frequent users of many of the strategies. Data from the writing strategy questionnaire indicated that the students employed more writing strategies in the while-writing stage compared to the prewriting and the revising stages. Baker and Boonkit's study (2004) showed that although there was no significant difference in the frequency of writing strategy used between high and low achievers, there were some differences in the types of strategies used. The low achievers seemed to start writing without having any plans and frequently used the translation strategy throughout the writing process.

\section{Method}

\subsection{Objectives}

The study aimed to examine the strategy use for essay writing among ESL students of different proficiency levels. Specifically the study aimed to answer the following questions:

1) What are the writing strategies most frequently used by ESL students when writing English essays?

2) What are the writing strategies most frequently used by high-intermediate level English proficiency students?

3) What are the writing strategies most frequently used by low English proficiency ESL students?

4) Is there any significant difference in most frequently used strategies between high-intermediate and low proficiency ESL students?

It is hoped that the study would gather helpful information to assist students to be aware of the strategies they use to develop their writing skills and to improve overall writing performance. The data from the study will also be beneficial for ESL teachers to recognize the role of individual differences i.e. different levels of English proficiency in learners' strategy use.

\subsection{Participants and Research Design}

A total of 50 Form Four upper secondary school students from a sub-urban area of the state of Selangor in Malaysia were involved in the study. They were divided into two groups based on the English language grade obtained in the national, standardized Malaysian Examination or Penilaian Menengah Rendah (PMR) that students sit at the end of their lower secondary level of schooling. Students with grade A and B are categorized as "high-intermediate proficiency", grade $\mathrm{C}$ and below as "low proficiency".

A 33-item 5 point Likert scale questionnaire on writing strategy use was adapted from Petric and Czarl's writing strategy questionnaire in their published article Validating a Writing Strategy Questionnaire (Petric \& Czarl, 2003). In the conclusion of the article, the authors offer some suggestions for modifications of the questionnaire so that it would better suit investigations into writing strategies in future research. Some changes were made to the questionnaire based on these suggestions. A bilingual questionnaire was prepared for the subjects from different proficiency levels. Dornyei and Taguchi (2010) state that translation of questionnaires has been widely practiced with the belief that "the quality of the obtained data increases if the questionnaire is presented in the respondents' own mother tongue" (p. 49). The writing strategy questionnaire was piloted and the Cronbach alpha coefficient was 0.78 . This instrument had a strong reliability (Jackson, 2006) and was suitable for this study. Descriptive and inferential statistics were used to analyze the quantitative data collected from the survey. The frequency of strategy use was grouped into three levels of high strategy use, medium strategy use and low strategy use listed by Oxford (1990).

\section{Results}

\subsection{Writing Strategies Most Frequently Used by ESL Students}

The overall mean of writing strategies is $3.10(\mathrm{M}=3.10)$ with standard deviation $.429(\mathrm{SD}=.429)$ and according to Oxford (1990) this mean is at Medium Level. This shows that the overall use of writing strategies by students in the English language classroom is at medium level. 
Table 1. Summary of writing strategy use in each stage

\begin{tabular}{lll}
\hline Stage & Mean & SD \\
\hline Prewriting & 2.87 & .528 \\
While-writing & 3.45 & .471 \\
Revising & 2.88 & .558 \\
Overall writing strategies & 3.10 & .429 \\
\hline
\end{tabular}

In terms of stages of writing (refer to Table 1.0), the findings show that the students used more strategies at the while-writing stage $(\mathrm{M}=3.45 ; \mathrm{SD}=.472)$ as compared to strategies at the revising stage $(\mathrm{M}=2.88 ; \mathrm{SD}=.558)$ and strategies at the prewriting stage $(\mathrm{M}=2.87 ; \mathrm{SD}=.528)$.

Table 1.1 provides in detail the individual strategies most frequently employed by students when writing English essays in the classroom.

Table 1.1. Overall writing strategies most frequently used

\begin{tabular}{|c|c|c|c|c|c|c|c|c|c|}
\hline & vriting stage & $\mathrm{N}$ & IN & $\mathrm{S}$ & FR & $\mathrm{A}$ & Mean & SD & Level \\
\hline$\overline{1}$ & Think and plan in mind & 0 & 2 & 8 & 17 & 23 & 4.22 & .864 & High \\
\hline & & & $4.0 \%$ & $16.0 \%$ & $34.0 \%$ & $46.0 \%$ & & & \\
\hline & ing stage & $\mathrm{N}$ & IN & S & FR & A & Mean & SD & Level \\
\hline 1 & Start with introduction & 0 & 0 & 6 & 8 & 36 & 4.60 & .700 & High \\
\hline & & & & $12.0 \%$ & $16.0 \%$ & $72.0 \%$ & & & \\
\hline 2 & Reread what is written to get & 3 & 1 & 3 & 20 & 23 & 4.18 & 1.063 & High \\
\hline & idea t & $6.0 \%$ & $2.0 \%$ & $6.0 \%$ & $40.0 \%$ & $46.0 \%$ & & & \\
\hline 3 & Use word in mother tongue & 3 & 2 & 16 & 13 & 16 & 3.74 & 1.139 & High \\
\hline & $\begin{array}{l}\text { before finding appropriate } \\
\text { English word }\end{array}$ & $6.0 \%$ & $4.0 \%$ & $32.0 \%$ & $26.0 \%$ & $32.0 \%$ & & & \\
\hline 4 & Use bilingual dictionary & 8 & 4 & 6 & 10 & 22 & 3.68 & 1.504 & High \\
\hline & & $16.0 \%$ & $8.0 \%$ & $12.0 \%$ & $20.0 \%$ & $44.0 \%$ & & & \\
\hline 5 & Ask help from classmates or & 3 & 5 & 13 & 15 & 14 & 3.64 & 1.174 & High \\
\hline & teacher when face difficulties & $6.0 \%$ & $10.0 \%$ & $26.0 \%$ & $30.0 \%$ & $28.0 \%$ & & & \\
\hline 6 & Stop to read after each & 2 & 6 & 17 & 10 & 15 & 3.60 & 1.161 & High \\
\hline & sentence & $4.0 \%$ & $12.0 \%$ & $34.0 \%$ & $20.0 \%$ & $30.0 \%$ & & & \\
\hline 7 & Stop after few sentences & 2 & 5 & 13 & 23 & 7 & 3.56 & .993 & High \\
\hline & covering an idea & $4.0 \%$ & $10.0 \%$ & $26.0 \%$ & $46.0 \%$ & $14.0 \%$ & & & \\
\hline & sing stage & $\mathrm{N}$ & IN & $\mathrm{S}$ & FR & $\mathrm{A}$ & Mean & $\mathrm{SD}$ & Level \\
\hline 1 & Check mistakes after feedback & & 3 & 10 & 18 & 17 & 3.90 & 1.074 & High \\
\hline & frol & $4.0 \%$ & $6.0 \%$ & $20.0 \%$ & $26.0 \%$ & $34.0 \%$ & & & \\
\hline 2 & Check if essay fulfils & 3 & 4 & 14 & 13 & 16 & 3.70 & 1.182 & High \\
\hline & req & $6.0 \%$ & $8.0 \%$ & $28.0 \%$ & $26.0 \%$ & $32.0 \%$ & & & \\
\hline
\end{tabular}

Table 1.1 indicates that there are ten strategies most frequently used by the students when they write essays in English. The most frequently used strategy at the prewriting stage is Think and plan in mind $(\mathrm{M}=4.22$; $\mathrm{SD}=.864$ ). In comparison to the other two stages, the writing stage showed the most number of frequently used strategies. Seven out of thirteen strategies in the writing stage are most frequently used by the students. Most of the students chose Start with introduction $(\mathrm{M}=4.60 ; \mathrm{SD}=.700)$ as their initial strategy when they begin writing 
their essays. Another frequently used strategy is Reread what is written to get idea to continue $(\mathrm{M}=4.18 ; \mathrm{SD}=$ 1.06). Next, the students chose the strategy Use word in mother tongue before finding appropriate English word $(\mathrm{M}=3.74 ; \mathrm{SD}=1.14)$. Perhaps that is why they preferred to Use the bilingual dictionary $(\mathrm{M}=3.68 ; \mathrm{SD}=1.50)$. Apart from that, a majority of the students chose to Ask help from classmates or the teacher when faced with difficulties $(\mathrm{M}=3.64 ; \mathrm{SD}=1.17)$. The students also preferred to Stop to read after each sentence $(\mathrm{M}=3.60$; $\mathrm{SD}=1.16)$ while chose Stop after few sentences covering an idea $(\mathrm{M}=3.56 ; \mathrm{SD}=.993)$. As for the revising stage, there were two strategies most frequently used by the students. A favourite choice seemed to be Check mistakes after feedback from teacher $(\mathrm{M}=3.90 ; \mathrm{SD}=1.07)$. In addition, the students chose to Check if essay fulfils requirements $(\mathrm{M}=3.70 ; \mathrm{SD}=1.18)$.

\subsection{Difference in Strategy Use Based on Proficiency Level}

Table 1.2. Mean and standard deviation of overall writing strategy between high-intermediate and low proficiency students

\begin{tabular}{lllll}
\hline Proficiency & $\mathrm{N}$ & Mean & SD & Level \\
\hline High-intermediate & 25 & 3.12 & .406 & Moderate \\
Low proficiency & 25 & 3.09 & .458 & Moderate
\end{tabular}

Table 1.2 shows the overall mean of writing strategies employed by the high-intermediate students $(\mathrm{M}=3.12$; $\mathrm{SD}=.406)$ which seemed to be slightly higher than the low proficiency group $(\mathrm{M}=3.09 ; \mathrm{SD}=.458)$. However, as also shown in Oxford's study (1990), both groups were moderate strategy users.

Further comparisons of strategy use at different stages of writing were made between the two groups (refer Table $1.3)$.

Table 1.3. Mean and standard deviation of writing strategy at different stages based on proficiency level

\begin{tabular}{lllllll}
\hline English Proficiency & \multicolumn{2}{c}{ Prewriting Stage } & \multicolumn{2}{c}{ Writing Stage } & \multicolumn{2}{c}{ Revising Stage } \\
\hline & Mean & SD & Mean & SD & Mean & SD \\
\hline $\begin{array}{l}\text { High-intermediate } \\
(\mathrm{n}=25)\end{array}$ & 2.98 & .450 & 3.43 & .407 & 2.88 & .571 \\
$\begin{array}{l}\text { Low proficiency } \\
(\mathrm{n}=25)\end{array}$ & 2.76 & .458 & 3.47 & .583 & 2.88 & .555 \\
\hline
\end{tabular}

The table also shows higher mean of strategy use at prewriting stage for the high-intermediate $(\mathrm{M}=2.98$; $\mathrm{SD}=.450)$ as compared to the low proficiency students $(\mathrm{M}=2.76 ; \mathrm{SD}=.583)$. However, the low proficiency group used more strategies at the writing stage $(\mathrm{M}=3.47 ; \mathrm{SD}=.407)$ when compared to the high-intermediate group. As for the revising stage, the findings indicated similar frequency use of strategies; high-intermediate $(\mathrm{M}=2.88$; $\mathrm{SD}=.555)$ and low proficiency $(\mathrm{M}=2.88 ; \mathrm{SD}=.571)$. The findings also revealed that only two out of eight prewriting strategies were most frequently used by the high-intermediate students. The students chose to Think and plan in mind $(\mathrm{M}=4.56 ; \mathrm{SD}=.583)$ and reported to Use WH questions to work on content $(\mathrm{M}=3.68 ; \mathrm{SD}=1.11)$. 
Table 1.4. Mean and standard deviation of prewriting strategies used by high-intermediate and low proficiency students

\begin{tabular}{|c|c|c|c|c|c|}
\hline \multicolumn{2}{|c|}{ Prewriting Strategies } & \multicolumn{2}{|c|}{ High-intermediate $(\mathrm{n}=25)$} & \multicolumn{2}{|c|}{ Low proficiency $(\mathrm{n}=25)$} \\
\hline & & $\overline{\text { Mean }}$ & SD & Mean & SD \\
\hline 1 & Think and plan in mind & $4.56^{*}$ & .583 & $3.88^{*}$ & .971 \\
\hline 2 & Write outline in English & 2.88 & 1.13 & 2.24 & 1.09 \\
\hline 3 & Write outline in MT & 2.36 & 1.31 & 2.72 & 1.57 \\
\hline 4 & Start writing without written or mental plan & 1.72 & .737 & 2.16 & 1.25 \\
\hline 5 & Look at essay models & 3.16 & 1.07 & 2.84 & 1.07 \\
\hline 6 & Note down related words and short notes & 2.68 & 1.21 & 2.20 & .913 \\
\hline 7 & Discuss content with classmates & 2.84 & 1.18 & 2.92 & 1.15 \\
\hline 8 & Use WH questions to work on content & $3.68 *$ & 1.11 & 3.12 & 1.09 \\
\hline
\end{tabular}

Note. *indicates high frequency use of strategies

As indicated in Table 1.4, one prewriting strategy most frequently used by the low proficiency students was also Think and plan in mind $(\mathrm{M}=3.88 ; .971)$. However, the reported mean was lower as compared to the high-intermediate group.

Table 1.5. Mean and standard deviation of while-writing strategies used by high-intermediate and low proficiency students

\begin{tabular}{|c|c|c|c|c|c|}
\hline \multicolumn{2}{|c|}{ While-writing Strategies } & \multicolumn{4}{|c|}{ High-intermediate $(n=25)$ Low proficiency $(n=25)$} \\
\hline & & Mean & SD & Mean & SD \\
\hline 1 & Start with introduction & $4.76^{*}$ & .523 & $4.44 *$ & .821 \\
\hline 2 & Stop to read after each sentence & 3.44 & .917 & $3.76^{*}$ & 1.36 \\
\hline 3 & Stop after few sentences covering an idea & 3.48 & .918 & $3.64 *$ & 1.08 \\
\hline 4 & Reread what is written to get idea to continue & $4.36^{*}$ & .569 & $4.00 *$ & 1.38 \\
\hline 5 & Go back to outline to make necessary changes & 3.52 & 1.16 & 3.16 & 1.11 \\
\hline 6 & Write bits of text in MT and translate & 2.68 & 1.40 & 3.20 & 1.38 \\
\hline 7 & Give full attention to grammar and vocabulary & 3.12 & 1.05 & 2.40 & 1.00 \\
\hline 8 & Simplify what to write & $3.56^{*}$ & .917 & 2.96 & 1.37 \\
\hline 9 & Use word in MT before find appropriate English word & 3.48 & 1.29 & $4.00 *$ & .913 \\
\hline 10 & Stop writing to look up for English word in dictionary & 3.28 & 1.28 & $3.60^{*}$ & 1.30 \\
\hline 11 & Use bilingual dictionary & 3.24 & 1.64 & $4.12 *$ & 1.24 \\
\hline
\end{tabular}

Note. ${ }^{*}$ indicates high frequency use of strategies

As reported earlier, the while-writing strategies were most frequently employed by both high-intermediate and low proficiency students. Table 1.5 shows in detail the while-writing strategies used by the students. The high-intermediate students chose to Start with introduction $(\mathrm{M}=4.76 ; \mathrm{SD}=.523)$ and Reread what is written to get idea to continue $(\mathrm{M}=4.36 ; \mathrm{SD}=.569)$. They would also Simplify what to write when they have difficulties expressing their thoughts on paper. However, the low proficiency students seemed to have used more strategies while writing. The most frequently used strategy was also to Start with introduction $(\mathrm{M}=4.44 ; \mathrm{SD}=.821)$. In contrast to the other group, the low proficiency students not only Reread what is written to get idea to continue $(\mathrm{M}=4.00 ; \mathrm{SD}=.138)$ but also Stop to read after each sentence $(\mathrm{M}=3.76 ; \mathrm{SD}=1.36)$ and Stop after few sentences covering an idea $(\mathrm{M}=3.64 ; \mathrm{SD}=1.08)$. They also reported to Use bilingual dictionary $(\mathrm{M}=4.12 ; \mathrm{SD}=1.24)$ and 
Use word in MT before find appropriate English word $(\mathrm{M}=4.00 ; \mathrm{SD}=.913)$. They would also Stop writing to look up for English word in dictionary $(\mathrm{M}=3.60 ; \mathrm{SD}=1.30)$ when they write essays in English.

Table 1.6. Mean and standard deviation of revising strategies used by high-intermediate and low proficiency students

\begin{tabular}{|c|c|c|c|c|c|}
\hline \multicolumn{2}{|c|}{ Revising Strategies } & \multicolumn{2}{|c|}{$\begin{array}{l}\text { High-intermediate } \\
(\mathrm{n}=25)\end{array}$} & \multicolumn{2}{|c|}{ Low proficiency $(n=25)$} \\
\hline & & Mean & SD & Mean & SD \\
\hline 1 & Read what is written after finished all & 3.32 & 1.43 & $3.68^{*}$ & 1.11 \\
\hline 2 & Hand in written paper without reading & 1.60 & .816 & 1.92 & 1.22 \\
\hline 3 & Use a dictionary when revising & 2.44 & 1.04 & 2.72 & 1.10 \\
\hline 4 & Make changes in vocabulary & 2.64 & .995 & 2.20 & 1.08 \\
\hline 5 & Make changes in sentence structure & 2.88 & 1.01 & 2.52 & .963 \\
\hline 6 & Make changes in structure of essay & 2.92 & .997 & 2.68 & 1.11 \\
\hline 7 & Make changes in the content of ideas & 2.80 & .957 & 2.88 & 1.01 \\
\hline 8 & Drop first draft and write again & 2.04 & 676 & 2.48 & 1.23 \\
\hline 9 & Check if essay fulfil requirements & $4.04 *$ & .978 & 3.36 & 1.29 \\
\hline 10 & Show text to somebody for opinion & 2.72 & 1.34 & 3.20 & 1.29 \\
\hline 11 & Compare papers with friends & 3.00 & 1.26 & 3.32 & 1.25 \\
\hline 12 & Check mistakes after feedback from teacher & $4.16^{*}$ & .800 & $3.64 *$ & 1.25 \\
\hline
\end{tabular}

Note. *indicates high frequency use of strategies

Table 1.6 shows the revising strategies most frequently used by both high-intermediate and low proficiency students. The high-intermediate students chose to Check mistakes after feedback from teacher $(\mathrm{M}=4.16$; $\mathrm{SD}=.800)$ and before that they would Check if essay fulfil requirements $(\mathrm{M}=4.04 ; \mathrm{SD}=.978)$. In contrast, the low proficiency students would Read what is written after finished all $(\mathrm{M}=3.68 ; \mathrm{SD}=1.11)$ and later Check mistakes after feedback from teacher $(\mathrm{M}=3.64 ; \mathrm{SD}=1.25)$.

A one-way between groups multivariate analysis of variance was performed to check any significant differences in writing strategy use between the high-intermediate and low proficiency students. Preliminary assumption testing was conducted to check for normality, linearity, univariate and multivariate outliers, homogeneity of variance-covariance matrices, and multicollinearity, with no serious violations noted.

Table 1.7. Multivariate test conducted for the writing strategies

\begin{tabular}{llllllll}
\hline Effect & Value & $\mathrm{F}$ & $\begin{array}{l}\text { Hypo. } \\
\mathrm{df}\end{array}$ & $\begin{array}{l}\text { Err } \\
\mathrm{df}\end{array}$ & Sig & $\begin{array}{l}\text { Partial } \\
\text { Squared }\end{array}$ & Eta \\
\hline $\begin{array}{l}\text { Proficiency } \\
\text { level }\end{array}$ & $\begin{array}{l}\text { Wilks' } \\
\text { Lambda .93 }\end{array}$ & 1.20 & 3.00 & 46.00 & .320 & .07 & \\
\hline
\end{tabular}

As shown in Table 1.7, there was no statistically significant difference between the high-intermediate and low proficiency students on the frequency of writing strategy use, $F(3,46)=1.20, p=.320$; Wilks' Lambda $=.93$; partial eta squared $=.07$.

These statistics suggest that English proficiency has no effect on the frequency of strategy use. In summary, English proficiency has affected the type of strategy use, rather than frequency of strategy use. The ESL students of differing ability have preference over different strategies but the frequency of strategy use has remained the same among them. 


\section{Discussion}

The purpose of the study was to examine the strategy use for essay writing among ESL students of different proficiency levels. The study also aimed to determine whether there was any significant difference in strategies most frequently used between high-intermediate and low proficiency students.

The present study found that writing strategies were moderately used by ESL students and this finding is consistent with the results discovered in Chen (2011). Consistent to Baker and Boonkit (2004), this study also found no significant difference in the frequency of writing strategy use between high-intermediate and low proficiency students. Although ESL students of differing proficiency level did use some kinds of strategies in the pre-writing stage, while-writing stage and revising stage, they were still not frequent users of many of them. More specifically, the students used more strategies in the writing stage than in the prewriting and revising stage. The strategy of thinking and having mental plan, which was most frequently used in the prewriting stage, was proven to be ineffective to help them develop ideas for their writing task. That was why, while writing, students most often stopped and reread either after each sentence or a few sentences covering one idea to help them continue writing. Earlier, Indra (2004) had discovered that writers who planned their ideas in outlines or in visual representations, performed better in writing. The results of the present study suggest that the ESL students are not good at generating ideas, planning or outlining before they start writing. Furthermore, in the revising stage, the ESL students seemed to focus more on making sure their writing fulfils the essay requirement suggesting the characteristic of surface writing approach as indicated by Hu and Chen (2007). Although they claimed to check mistakes after getting feedback from the teacher, their writing seemed to be the final draft as they did not make any attempt to rewrite the essay.

This study has revealed one important result which is that English proficiency has affected the type of strategy use, rather than frequency of strategy use. More specifically, the high-intermediate students were more concerned with thinking and planning, and outlining in English before they started their writing task. This resembles the characteristics of skilled writers in Mu and Carrington (2007) and Riduan and Lim (2009). High intermediate students were more conscious of advantages in certain writing strategies such as brainstorming that helps activate their own knowledge and ideas related to the writing topic. As indicated by Baker and Boonkit (2004), both successful and less successful learners differed in the frequency of English use. The low proficiency students used more translation strategy and used bilingual dictionaries to help them in their writing task.

However, both groups seemed to have focused more on grammar and vocabulary while writing. Both groups were also concerned with the organization of the essay as their revising strategies were only restricted to ensuring that the essays follow certain requirements. Other revising strategies were not frequently used by the students including the high-intermediate group. This is not consistent with the findings of Chien (2010) in which the high achievers in his study had focused on revising and editing and perceived writing as a process to express ideas and make meaningful changes, a way of thinking and clarifying meanings for themselves. There is thus a need for students to engage in more reviewing actions for it can enhance and improve quality of writing.

\section{Conclusion}

Promoting writing strategy use to help improve writing performance can be a great challenge for ESL teachers. One of the results has revealed that writing strategies are not frequently used, rather are moderately used by ESL students when writing English essays. In addition, more strategies are used in the writing stage than in the pre-writing stage while the revising strategies are used the least. This calls for strategy training activities among students in the ESL classrooms. Specifically, the strategies used in the pre-writing stage deserve more attention. It is essential for students to be taught how to brainstorm to generate ideas and plan by making a well-rounded outline before they actually start writing. This would help ease the writing process itself and students could focus on conveying the intended meaning rather than continuously searching for ideas to continue writing. The students should be taught more revising strategies to help improve their quality of writing. However, teachers must be aware of the difficulties students face when writing English essays and allow students to try out strategies that best work for them. It should not be presumed that the act of writing in one's first language is similar to writing in one's second language. The first and second language learners may not approach a writing task or attend to feedback in the same way.

\section{References}

Baker, W., \& Boonkit, A. (2004). Learning strategies in reading and writing: EAP contexts. Regional Language Centre Journal, 35(3), 299-328. http://dx.doi.org/10.1177/0033688205052143 
Begum, R. (2005). A study of the learning strategies of low achievers of English as a Second Language in Selangor, Malaysia (Unpublished PhD thesis). Universiti Putra Malaysia.

Chen, Y. (2011). Study of the writing strategies used by Chinese non-English majors. Theory and Practice in Language Studies, 1(3), 245-251. http://dx.doi.org/10.4304/tpls.1.3.245-251

Chien, S. (2010). Enhancing English composition teachers' awareness of their students' writing strategy use. The Asia-Pacific Education Researcher, 19(3), 417-438.

Chitravelu, N., Sithamparam, S., \& Teh S. C. (2005). ELT Methodology: Principles and Practice. Selangor: Penerbit Fajar Bakti.

Congjun, M., \& Carrington, S. (2007). An investigation of three Chinese students' writing strategies. TESL-EJ, 11(1). Retrieved December 24, 2010, from http://tesl-ej.org/results.html

Cumming, A. (1989). Writing expertise and second language proficiency. Language Learning, 39, 81-141.

Dornyei, Z., \& Taguchi, T. (2010). Questionnaires in Second Language Research: Construction, Administration and Processing (2nd ed.). New York: Routledge.

Hu, G. W., \& Chen, B. (2007). A protocol-based study of university-level Chinese EFL learners' writing strategies. English Australia Journal, 23(2), 37-35. Retrieved December 27, 2010, from http://qa.englishaustralia.com.au/index.cgi? $\mathrm{E}=$ hcatfuncs\&PT $=$ sl $\& X=$ getdoc\&Lev1 $=$ pub_jour_23_\&Lev2= EAJ_23_2_hu

Hyland, K. (2008). Writing theories and writing pedagogies. Indonesian Journal of English Language Teaching, 4(2), 91-110.

Jackson, S. L. (2006). Research Methods and Statistics: A Critical Thinking Approach (2nd ed.). USA: Thomson Wadsworth.

Kementerian Pelajaran Malaysia (Ministry of Education). (2000). Sukatan Pelajaran Bahasa Inggeris (English language Syllabus). Kuala Lumpur.

Lay, N. D. S. (1982). Composing processes of adult ESL learners: A case study. TESOL Quarterly, 16(3), 406.

Lembaga Pelajaran Malaysia (Malaysia Education Board). (2009). Pengumuman Analisis Keputusan SPM 2009. Putrajaya.

Nunan, D. (1999). Second Language Teaching and Learning. USA: Heinle \& Heinle Publishers.

Oxford, R. (1990). Language Learning Strategies: What every teacher should know. Rowley: House.

Petric, B., \& Czarl, B. (2003). Validating a writing strategy questionnaire. System, 31, 187-215. http://dx.doi.org/10.1016\%2Fj.jbtep.2010.12.003

Polio, C., Fleck, N., \& Leder, N. (1998). "If only I had more time”: ESL learners' changes in linguistic accuracy on essay revisions. Journal of Second Language Writing, 7, 43-68. http://dx.doi.org/10.1016/S1060-3743(98)90005-4

Raimes, A. (1985). What unskilled ESL students do as they write: A classroom study of composing. TESOL Quarterly, 19(2), 229-258.http://dx.doi.org/ 10.2307/3586828

Ridhuan, M., \& Abdullah, T. L. (2009). The writing strategies used by Engineering ESL Malay learners. Conference of the International Journal of Arts \& Sciences. Retrieved December 27, 2010, from http://eprints.utp.edu.my/2035/

Stapa, S. H., \& Abdul Majid, A. H. (2006). The use of first language in limited English proficiency classes: Good, bad or ugly? Jurnal e-Bangi, 1(1), 1-12. Retrieved March 28, 2011, from http://eprints.ukm.my/24/1/sitihami-edited1.pdf

Subramaniam, I. D. (2004). The Composing Process of Skilled and Unskilled Chinese and Indian Students: A Case Study (Unpublished Master Thesis). Univerisiti Kebangsaan Malaysia.

Wang, W. Y., \& Wen, Q. F. (2002). L1 use and English writing quality. Journal of Foreign Languages Research, 4, 64-76.

Zamel, V. (1983). The composing processes of advanced ESL learners: Six case studies. TESOL Quarterly, 17 , 165-187. 